\title{
Biogenesis of Silver Nanoparticles Using Penicillium fellutanum and Determination of its Antibacterial Activity
}

\section{Nida Tabassum Khan*, Jibran Jameel and Saad Umer Abdul Rehman}

Department of Biotechnology, Faculty of Life Sciences and Informatics, Balochistan University of Information Technology, Engineering and Management Sciences, (BUITEMS), Quetta, Pakistan

\begin{abstract}
Silver nanoparticles were produced from cell free extract of Penicillium fellutanum with aqueous silver nitrate. The synthesized silver nanoparticles were produced in colloidal form outside the fungal cell in the external yeast malt extract (YM) media. Visual change in the color of the extract from deep yellow to grey indicates bioreduction of silver metal ions resulting in silver nanoaprticles synthesis. The reaction mixture was characterized by UV-visible spectrometry and absorption was measured from $350 \mathrm{~nm}$ to $450 \mathrm{~nm}$ and $\lambda$-max was found to be $430 \mathrm{~nm}$. Antibacterial efficacy of AgNPs was investigated using disc diffusion method against the bacteria Staphylococcus aureus, Escherichia coli, Aeromonas hydrophila and Klebsiella pneumoniae and was found to be effective antibacterial agent. Thus Penicillium fellutanum could be used as a source of silver nanoparticles, an ecofriendly alternative process for the mycosynthesis of stable AgNPs with future applications in biomedical based on its antibacterial properties.
\end{abstract}

Keywords: Penicillium fellutanum; AgNPs; Yeast malt extract; BUITEMS

\section{Introduction}

In recent years nanoparticles have been produced by industries for commercial application having many benefits. Biosynthesis of nanoparticles attracts many researchers and industries to explore microorganisms as the perfect biological system for the production of different nanoparticles. The metabolic activity of these microorganisms enables the extra cellular or intracellular synthesis of nanoparticles utilizing different mode of synthesis [1-4]. Microorganisms possess the capability to minimize the toxicity of the metal ions through bioreduction or by the formation of insoluble complexes with metal ion in the form of colloidal particles. According to Vijayaraghavan and Nalini, in comparison, biologically synthesized nanoparticles have proved to be better than the chemically synthesized ones due to a better control over the crystal growth because of slower kinetics which reduces the overall investment involved in nanoparticle synthesis [5]. Not only reduction in the overall cost makes it less expensive process but also it is an environmental friendly method because it does not involve the use of toxic chemicals that are expensive and harmful for the environment as used in non-biological synthetic procedures for the synthesis of nanoparticles of poor morphology. Therefore nanoparticles of distinct morphology can be obtained through the optimization of culture conditions using biological organisms. In present work AgNPs were fabricated using Penicillium fellutanum extract incubated with silver nitrate solution and its antibacterial activity was tested against various pathogenic bacteria.

\section{Materials and Methods}

\section{Fungal biomass production}

Penicillium fellutanum was isolated from soil and cultured was grown in $1 \mathrm{~L}$ yeast malt extract (YM) broth media which consists of glucose $(10 \mathrm{~g})$, malt extract $(3 \mathrm{~g})$, peptone $(5 \mathrm{~g})$ and yeast extract (3 g) dissolved in $1000 \mathrm{ml}$ of distilled water. The culture medium was autoclaved for $15 \mathrm{~min}$ at $121^{\circ} \mathrm{C}$ at $15 \mathrm{psi}$ (pound/square inches). The media was inoculated with Penicillium fellutanum culture in sterile air under Laminar flow cabinet by the help of sterilized wire loop. Incubation of the cultured flasks on a rotatory shaker at $150 \mathrm{rpm}$ for 72 hours was done at room temperature.

\section{Penicillium fellutanum live cell filtrate}

Penicillium fellutanum mycelia were filtered using Whatman's filter paper no.42 after 72 hours of incubation. The obtained live cell filtrate was further filtered through polyvinylidene fluoride (PVDF) membrane to obtain cell free fungal extract. The filtrate was then centrifuged at $10000 \mathrm{rpm}$ for $20 \mathrm{~min}$.

\section{Biogenesis of silver nanoparticles}

$10 \mathrm{ml}$ cell free fungal extract was than incubated with $90 \mathrm{ml}$ of 1 $\mathrm{mM} \mathrm{AgNO}{ }_{3}$ in the dark to nullify any photochemical reaction at $25^{\circ} \mathrm{C}$ for $48 \mathrm{hrs}$. The change in color of the experimental flask containing fungal filtrate incubated with $\mathrm{AgNO}_{3}$ results in the formation of AgNPs. Control containing freshly prepared YM media with aqueous silver nitrate was run simultaneously with the experimental flasks. Experiment and control were performed in triplicates.

\section{Confirmation of silver nanoparticles}

The reaction mixture was characterized by UV visible spectrometry (JENWAY 6305) and absorption was measured from $350 \mathrm{~nm}$ to $450 \mathrm{~nm}$ to determine $\lambda$ max.

\section{Antibacterial property}

Antibacterial efficacy of AgNPs was investigated against the bacteria Staphylococcus aureus, Escherichia coli, Aeromonas hydrophila and Klebsiella pneumoniae on YM agar plates (agar (20 g), glucose (10 $\mathrm{g})$, malt extract $(3 \mathrm{~g})$, peptone $(5 \mathrm{~g})$ and yeast extract $(3 \mathrm{~g})$ ) dissolved

*Corresponding author: Nida Tabassum Khan, Department of Biotechnology, Faculty of Life Sciences and Informatics, Balochistan University of Information Technology Engineering and Management Sciences, (BUITEMS), Quetta, Pakistan, Tel: 00368164903; E-mail: nidatabassumkhan@yahoo.com

Received: September 19, 2016; Accepted: December 12, 2016; Published December 15, 2016

Citation: Khan NT, Jameel J, Rehman SUA (2016) Biogenesis of Silver Nanoparticles Using Penicillium fellutanum and Determination of its Antibacterial Activity. Biochem Anal Biochem 5: 305. doi: 10.4172/2161-1009.1000305

Copyright: (C) 2016 Khan NT, et al. This is an open-access article distributed unde the terms of the Creative Commons Attribution License, which permits unrestricted use, distribution, and reproduction in any medium, provided the original author and source are credited. 


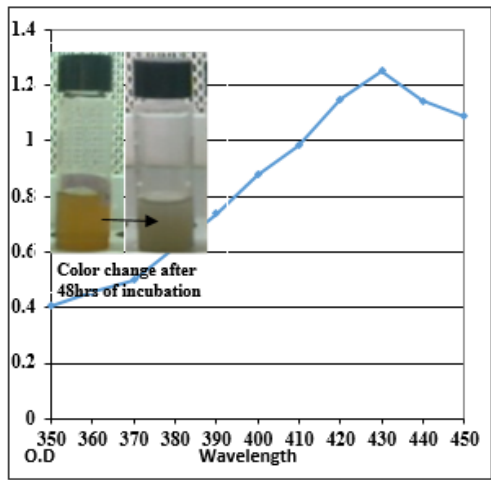

Figure 1: $\lambda$-max of Penicillium fellutanum reaction mixture (fungal filtrate with $\mathrm{AgNO}_{3}$ ).

\begin{tabular}{|c|c|c|}
\hline S.no & Test pathogens & $\begin{array}{c}\text { Zone of inhibition }(\mathbf{c m}) \text { Silver } \\
\text { nanoparticles } \mathbf{( 4 0} \boldsymbol{\mu L})\end{array}$ \\
\hline 1 & Aeromonas hydrophila & 0.9 \\
\hline 2 & Escherichia coli & 1.0 \\
\hline 3 & Klebsiella pneumoniae & 0.6 \\
\hline 4 & Staphylococcus aureus & 0.9 \\
\hline
\end{tabular}

Table 1: Anti-bacterial efficacy of AgNPs.

in $1000 \mathrm{ml}$ of distilled water by disc diffusion method. The culture medium was autoclaved for $15 \mathrm{~min}$ at $121^{\circ} \mathrm{C}, 15 \mathrm{psi}$ (pound/square inches). Before pouring $0.5 \mathrm{ml}$ antibiotic ampicillin was added to the medium to inhibit bacterial contamination and $1 \mathrm{ml}$ of $10 \%$ sterilized tartaric acid solution to adjust $\mathrm{pH}$ of media (4.2-4.5). The surface of the agar was inoculated with the test pathogens. Then sterile discs of size one centimeter were prepared and placed on agar surface impregnated with $40 \mu \mathrm{L}$ silver nanoparticle solution. Incubation was done at $37^{\circ} \mathrm{C}$ for 48 hrs. Calliper was used to measure the diameter of the inhibition zone. Silver nitrate solution impregnated discs were used as control.

\section{Results and Discussion}

Bioreduction of silver metal ions were observed by a gradual change in the color of the experimental flask from deep yellow to grey is due to the excitation of plasmon vibrations with AgNPs and the absorbance maximum absorbance was observed at $430 \mathrm{~nm}$ as shown by the UV-Visible spectra [6,7] (Figure 1). UVvisible spectra clearly indicates a single peak depicting synthesis of spherical shaped AgNPs with uniform distribution and no aggregation of the nanoparticles were observed [8-10].

The mechanistic aspect behind the invitro synthesis of AgNPs under standard lab conditions was not known until it was hypothesized later that reduction of silver metal ions was carried out by NADPH dependant enzyme nitrate reductase which forms its corresponding AgNPs. Antibacterial efficacy of AgNPs was tested against bacteria including Staphylococcus aureus, Escherichia coli, Aeromonas hydrophila and Klebsiella pneumoniae [11] and diameter of the inhibition zone was measured in centimeters (Table 1).

AgNPs synthesized from Penicillium fellutanum filtrate showed enhanced antibacterial effect against E. coli, Aeromonas hydrophila and Staphylococcus aureus as the measured diameter of the inhibition zone was found to be $1 \mathrm{~cm}, 0.9 \mathrm{~cm}$ and $0.9 \mathrm{~cm}$ respectively. However moderate antibacterial effect was seen against Klebsiella pneumoniae. The mechanism of inhibition is still unknown but the possible proposed assumption is the ionic binding of AgNPs to the surface of the bacterial cell or by means of AgNPs binding to the thiol group of the enzymes $[12,13]$.

\section{Conclusion}

Biosynthetic approach for silver nanoparticle synthesis is a novel approach using fungi as the biological organism. For example Penicillium fellutanum could be used as a source of silver nanoparticles, an ecofriendly alternative process for the mycosynthesis of stable AgNPs with enhanced antibacterial activity. However, studying the novel shape and size dependent physical and chemical properties of nanoparticles and their subsequent interaction could help in understanding its antibacterial mechanism and will lead to the development of a new range of antibacterial agents with widespread clinical applications.

\section{References}

1. Chakraborty N, Pal R, Ramaswami A, Nayak D, Lahiri S (2006) Diatom: A potential bio-accumulator of gold. J Radioanal Nucl Chem 270: 645-649.

2. Parial D, Patra HK, Dasgupta AKR, Pal R (2012) Screening of different algae for green synthesis of gold nanoparticles. European J Phycology 47: 22-29.

3. Nethradevi C, Sivakumar P, Renganathan S (2001) Green synthesis of silver nanoparticles using Datura metel flower extract and evaluation of their antimicrobial activity. International Journal of Nanomaterials and Biostructures 2: $16-21$.

4. Nayak RR, Pradhan N, Behera D (2011) Green synthesis of silver nanoparticle by Penicillium purpurogenum NPMF: The process and optimization. J Nanopart Res 13: 3129-3137.

5. Vijayaraghavan K, Nalini SPK (2010) Bio-templates in the green synthesis of silver nanoparticles. Biotechnol J 5: 1098-1110.

6. Henglein A (1993) Physicochemical properties of small metal particles in solution: Microelectrode reactions, chemisorption, composite metal particles, and the atom-to- metal transition. J. Phys Chem B 97: 5457-5471.

7. Sastry M, Mayya KS, Bandyopadhyay K (1997) pH dependent changes in the optical properties of carboxylic acid derivatized silver colloidal particles. Colloids Surf 127: 221-228.

8. Feynman RP (1991) There's plenty of room at the bottom. Science 2549: 1300-1301.

9. Balaji DS, Basavaraja S, Deshpande R, Bedre D, Prabhakar BK, et al. (2009) Extracellular biosynthesis of functionalized silver nanoparticles by strains of Cladosporium cladosporioides fungus. Colloids Surf B 68: 88-92.

10. Mukherjee P, Ahmad A, Mandal D, Senapati S, Sainkar SR, et al. (2001) Bioreduction of $\mathrm{AuCl}_{4}$ ions by the fungus Verticillium $\mathrm{sp}$ and surface trapping of the gold nanoparticles formed. Angewante Chemie International Edition 40 3585-3588.

11. Lara HH, Garza-Trevino EN, Ixtepan-Turrent L, Singh DK (2011) Silver nanoparticles are broad-spectrum bactericidal and virucidal compounds. Journal of Nanobiotechnology 9: 2-8.

12. Prabhu N, Divya Raj T, Gowri YK, Siddiqua AS, Puspha JDI (2010) Synthesis of silver phyto-nanoparticles and their antibacterial efficacy. Digest: Journal of Nanomaterials and Biostructures 5: 185-189.

13. Prasad R, Kumar V, Prasad KS (2014) Nanotechnology in sustainable agriculture: Present concerns and future aspects. Afr J Biotechnol 13: 705-713. 